\title{
Implications of Graphic Cigarette Warning Labels on Smoking Behavior: An International Perspective
}

\author{
Minsoo Jung \\ Department of Health Science, College of Natural Science, Dongduk Women's University, Seoul, Korea
}

\begin{abstract}
Graphic warning labels (GWLs) have been developed as a representative non-price policy to block such marketing. This study investigated the current state and effect of the global introduction of GWLs and examines the future tasks related to GWLs. We systematically reviewed literatures on GWL and a tobacco control strategy in the past fifteen years. The policy of enforcing GWLs has spread globally based on the Framework Convention on Tobacco Control. GWLs are more effective than text warnings and are implemented in over 70 countries. The policy has showed the impact of GWLs as a preventive effect on adolescents' smoking, inducement of smoking cessation, reduction in the amount of tobacco smoked, and reduction in smoking rates. The success of an anti-smoking policy can manifests itself as an effect of individual policies, the rise of tobacco prices, and the introduction of GWLs.
\end{abstract}

(J Cancer Prev 2016;21:21-25)

Key Words: Tobacco use, Smoking cessation, Health policy, Health promotion

\section{INTRODUCTION}

Packaging is tobacco companies' primary means of marketing due to the strengthening of anti-smoking policy worldwide. ${ }^{1}$ Graphic warning labels (GWLs) have been developed as a costeffective policy for simultaneously inhibiting such marketing and conveying information on the health risks incurred by smoking. The introduction of GWLs is effective for attracting smokers' attention and publicizing the harmfulness of tobacco. ${ }^{2,3}$ Article 11 of the Framework Convention on Tobacco Control (FCTC) recommends the introduction of the GWL for at least $50 \%$ of the packet cover and enforces countries directly involved to comply within three years of adopting the Convention. In addition, the third general assembly of the FCTC in 2008 recommended the introduction of plain packaging to prevent the advertising effect through tobacco packs. ${ }^{4}$ Packing can have an effect of deluding consumers and promoting the sales of tobacco. The present study systematically reviews the current state and effect of the global introduction of GWLs and examines the future tasks related to GWLs.

\section{GRAPHIC WARNING LABELS AND RELATED DEBATES}

The GWLs were first introduced to Canadian consumers in 2001. Subsequently, the FCTC took effect in 2005 as an international effort to reduce deaths and illnesses due to tobacco, and rapidly increased the number of countries adopting GWL. In particular, Canada established the Tobacco Products Information Regulations in 2000 based on the Tobacco Act. ${ }^{5}$ As a result, tobacco packaging with GWLs, anti-smoking warning messages, and explanations on the emission and composition of toxic substances became mandatory. ${ }^{5}$ In the early introduction of GWLs, the area on the package was extended to at least 30\% of cigar, pipe tobacco, hookah, and smokeless tobacco packaging and to at least $50 \%$ for ordinary tobacco packs. ${ }^{5}$

Received February 15, 2016, Revised March 2, 2016, Accepted March 2, 2016

Correspondence to: Minsoo Jung

Department of Health Science, College of Natural Science, Dongduk Women's University, 60 Hwarang-ro 13-gil, Seongbuk-gu, Seoul 02748, Korea Tel: +82-2-940-4483, Fax: +82-2-940-4480, E-mail: mj748@dongduk.ac.kr, ORCID: Minsoo Jung, http://orcid.org/0000-0003-3317-6507

Copyright (C) 2016 Korean Society of Cancer Prevention

(c) This is an Open Access article distributed under the terms of the Creative Commons Attribution Non-Commercial License (http://creativecommons.org/licenses/by-nc/4.0) which permits unrestricted non-commercial use, distribution, and reproduction in any medium, provided the original work is properly cited. 
GWLs swiftly spread worldwide. For example, the Thai government in 2004 passed a law making it mandatory to attach GWLs on both the front and back sides, extending to $50 \%$ of the entire cigarette packs. ${ }^{6}$ The sizes of the GWLs have expanded to no less than $85 \%$ of a cigarette pack. The mandatory attachment of GWLs worldwide exceeds $82.5 \%$ in Australia and $80 \%$ in Uruguay. Obviously, the tobacco industry has strongly opposed restrictions through GWLs. The industry has argued that the harmfulness of tobacco is widely known already, and that the attachment of GWLs to the packaging violates trademark rights and copyrights and can incite the production of counterfeit tobacco. ${ }^{6}$ Such debates have led to scientific discussions on whether the future introduction of GWLs will reduce smoking rates.

It is reported that tobacco packaging has a greater marketing effect than do other consumer goods because the packaging is not discarded immediately after it has been opened. ${ }^{1.5}$ The packing is exposed to those around the tobacco users a countless number of times until all of the contents have been used up. In other words, adoption of GWLs is intended more to stop tobacco companies' from marketing than to provide health education to consumers by publicizing the risks and harmfulness of smoking. In fact, tobacco companies have developed tobacco packs with 'cool' or 'feminine' images to attract the attention of the young and women and to strengthen their brand images through stealth marketing. ${ }^{5}$ Consequently, some tobacco companies have lawsuits against the US Food and Drug Administration. ${ }^{7}$ This has led to debates on the introduction of GWL effects.

In spite of the many debates, the effects of GWLs on smokers' attitudes toward smoking seem clear. The fear and anger generated when smokers are exposed to GWLs have a positive effect on smoking cessation and a negative effect on smoking. ${ }^{8}$ According to a recent study published in Tobacco Control, the strength of emotional responses generated after exposure to GWLs determined the effect of GWLs. ${ }^{9}$ When functional magnetic resonance imaging of neural responses generated after exposing smokers to GWLs were analyzed, the images aroused strong emotional reactions, which increase cognitive efforts that accompany information processing. ${ }^{10}$ This increases the memory of the images and reduces the desire to smoke. ${ }^{9,10}$ In other words, smokers exposed to GWLs exhibited more fear and a stronger intention to quit smoking than did smokers exposed to simple warning messages.

According to data announced by the Canadian Cancer Society in 2014, GWLs have been introduced to seventy-six countries worldwide as of 2015. After all members of the European Union adopt GWLs in 2016, GWLs will be implemented in at least ninety-four countries. ${ }^{5}$ GWLs were adopted by only five countries in the early 2000s, twenty-nine countries from 2006 to 2010, and forty-two countries from 2011 to $2015 .^{5}$ GWLs are scheduled to be adopted by eighteen countries in 2016. Thus, insertion of the GWLs on tobacco packaging can be seen as a global trend.

\section{SCIENTIFIC EVIDENCE OF GRAPHIC WARNING LABELS}

The introduction of GWLs may induce smokers to quit smoking, and thus lowers tobacco consumption. In the case of Canada, smoking cessation motivation is reported to have increased among half of the smokers since the adoption of GWLs. ${ }^{5,11}$ In Australia, GWLs have aroused smoking cessation motivation among $60 \%$ of the smokers. ${ }^{12}$ Subsequently, one-third of the smokers have attempted to quit smoking. Likewise, in Thailand, the intention to quit smoking has increased among half of the smokers since the introduction of GWLs. ${ }^{13}$ An increase in smokers' smoking cessation efforts and actual smoking cessation rates after the adoption of the GWL has affected tobacco consumption. In the case of Singapore, $28 \%$ of smokers reported smoking fewer cigarette because of GLWs in $2004 .^{14}$ In addition, the adoption of GWLs has inhibited the number of new smokers and induced current smokers to quit smoking. ${ }^{15}$ Importantly, a major cause in the reduction of tobacco consumption lies in the inhibition by new smokers, including adolescents. According to reports on the population conducted in Australia and Canada, the smoking prevention effects of GWLs amount to a maximum of $60 \% .{ }^{16,17}$ The introduction of GWLs more effectively inhibits an increase in the number of smokers than do warning messages. This has been confirmed for adolescents in European countries such as Greece. ${ }^{18}$

Second, the introduction of GWLs may decrease the overall smoking rates. In the case of price policy, smoking rates drop according to an increase in tobacco prices. ${ }^{19}$ However, tobacco consumption often returns to the normal consumption rate with the passage of time. Yet, the adoption of GWLs exhibits a continuous smoking decrease effect in comparison with price policy. ${ }^{20}$ In the case of Canada, the introduction of GWLs is estimated to have led to a drop in the number of smokers by approximately $12 \%$ to $19 \%{ }^{19,20}$ of course, predicting a uniform decrease in smoking rates is difficult because the strength of graphic labels and the presence of other warning messages differ by country. Nevertheless, according to research by Huang et al., ${ }^{19}$ smoking rates will decrease by a maximum of $5 \%$ if Canada's 
GWLs are applied to the United States. What is important is that the adoption of GWLs generally leads to a continuous drop in smoking rates. In the case of Turkey, men's smoking rate was approximately $44 \%$ in 2008 and dropped to $39.0 \%$ in 2010 and $37.3 \%$ in 2012 due to the introduction of GWLs. ${ }^{21}$

Third, the introduction of GWLs leads to additional effects such as the conveyance of health information from the perspective of health communication. In Australia and Thailand, the ability to convey information has been strengthened when warning messages were combined with GWLs. ${ }^{12}$ In the case of China and Mexico, senior citizens, women, and low socioeconomic status groups have been shown to recognize information more effectively on diseases that are caused by smoking through GWLs. ${ }^{2,22}$ In addition, according to the results of comparative studies among countries, tobacco consumers more accurately recognized diseases due to cigarette smoke substances (3.4 times as much for carbon monoxide and 3.8 times as much for potassium cyanide) and smoking (2.7 times as much for impotence and 1.6 times as much for both strokes and cancer occurrence) with GWLs. ${ }^{23}$ The correct awareness of health information has a potential effect of inducing smokers to voluntarily enhance the use of smoking cessation services. In the case of the Netherlands, the number of calls to smoking cessation hotlines has increased by 3.5 times since the introduction of GWLs. ${ }^{24}$ Brazil and New Zealand have shown similar effects. ${ }^{24-26}$

Fourth, the adoption of GWLs may create social benefits in diverse ways. However, when smoking rates drop because of GWLs, governments experience a drop in tax. The introduction of GWL policies decreases related diseases, and thus ultimately benefits society. In the case of Canada, the adoption of GWLs has extended the life span, which has yielded a net benefit of approximately four billion dollars. ${ }^{27}$ In the case of the United Kingdom, the introduction of GWLs has resulted in a decrease in the number of smokers by $0.5 \%$ and a net benefit of 206.29 million pounds because of an increase in the economic value of the living population and the curtailment of medical expenses. ${ }^{28}$ In Australia, a net benefit of 2.9 billion dollars has been generated because of a decrease in smoking rates, extension of the life span, improvement in health, the curtailment of medical expenses, and an increase in the consumption of non-tobacco products. ${ }^{29}$

\section{SEVERAL TASKS FOR THE FUTURE}

GWLs are cited as the most cost-effective policy from a diverse set of anti-smoking policies. ${ }^{30}$ GWLs are an evidence-based policy whose effect has been proven by countries that have already adopted them. Consequently, when GWLs are implemented with price policy that raises tobacco prices, they are expected to effectively decrease smoking rates and the number of new smokers, and prevent adolescent smoking. ${ }^{18}$ However, several tasks remain.

First is the task of effective application by the FCTC. The FCTC stipulates within the scope allowed by the countries respective constitutions, 'comprehensive ban actions,' for the advertisement, and sales promotion and support for tobacco. ${ }^{4}$ For example, India implements comprehensive ban actions on advertisements, sales promotions, and support regarding tobacco in accordance with the FCTC. ${ }^{4}$ Tobacco advertisements are prohibited on the broadcast media such as television and radio, and publications such as magazines and newspapers. On the other hand, signatories of the FCTC have an obligation to implement this clause by modifying their respective laws and institutions related to the packaging and labeling of tobacco products within three years of convention ratification. ${ }^{4}$ Consequently, the states parties have included health warning messages and graphic labels on at least $30 \%$ of the packaging and have strongly restricted tobacco packaging, which has been used as a means for marketing tobacco. For example, Australia in October 2011 passed a law that prohibits the inclusion of advertising statements, images, and company logos on cigarette packs. ${ }^{4}$ This law applies so-called 'plain packaging,' and thus requires to uniformize the color of all cigarette packs as drab dark brown and to include chilling images demonstrating the harm of smoking instead of advertising images and company logos. ${ }^{4}$ It is fair to say that the warnings are important for providing useful information to consumers.

Second, developing various and effective GWLs in a sociocultural context and smoking characteristics for each country is necessary. GWLs mainly affect smokers through fear, which can yield disparate effects according to the conveyed contents, themes, and messages. Consequently, the effectiveness and effect of GWLs on smokers for each country must be analyzed meticulously.

Third, longitudinal studies comparing long-term changes in smoking rates before and after the introduction of GWLs need to be conducted. In addition, scientifically reviewing both price policies and various non-price policies that yield the greatest smoking cessation effect is necessary. Such a task will continuously prove the long-term effect of a policy, and thus secure the validity of and justification for the introduction of the policy and expand related future policies. Economic evaluation and cost-benefit analysis must also be conducted. To meticulously grasp the policy effect, it is necessary to consider whether 
the goals have been achieved by adopting GWLs and who are to be the objects of persuasion. Smokers vs. non-smokers, heavy smokers vs. occasional smokers, and adolescents vs. adults are possible. The effect of GWLs may be most dramatic for occasional smokers or adolescents in their early to mid-teenaged years that have not yet started to smoke rather than heavy smokers who have formed the habit.

\section{CONCLUSION}

This paper attempted to summarize what is happening globally in terms of GWLs, how effective the implementation of GWLs is on decreasing tobacco rates, and what the next steps are for GWLs around the world. The success of an anti-smoking policy can manifests itself as an effect of individual policies, the rise of tobacco prices, and the introduction of GWLs. Success need to be evaluated as an integrated effect of diverse policies that includes the rise of tobacco prices and the extension of non-smoking areas.

\section{CONFLICTS OF INTEREST}

No potential conflicts of interest were disclosed.

\section{REFERENCES}

1. Wakefield M, Morley C, Horan JK, Cummings KM. The cigarette pack as image: new evidence from tobacco industry documents. Tob Control 2002;11 Suppl 1:173-80.

2. Strasser AA, Tang KZ, Romer D, Jepson C, Cappella JN. Graphic warning labels in cigarette advertisements: recall and viewing patterns. Am J Prev Med 2012;43:41-7.

3. Hammond D. Health warning messages on tobacco products: a review. Tob Control 2011;20:327-37.

4. U.S. Department of Health and Human Services. The health consequences of smoking -50 years of progress: a report of the surgeon general. Atlanta, GA, U.S. Department of Health and Human Services, Centers for Disease Control and Prevention, National Center for Chronic Disease Prevention and Health Promotion, Office on Smoking and Health, 2014.

5. Canadian Cancer Society. Cigarette Package Health Warnings: International Status Report. 4th ed. Ottawa, Canadian Cancer Society, 2014.

6. Vathesatogkit P, Charoenca N. Tobacco control: lessons learnt in Thailand. Indian J Public Health 2011;55:228-33.

7. R.J. Reynolds Tobacco Company, Lorillard Tobacco Company, Commonwealth Brands, Inc., Liggett Group LLC, Santa Fe Natural Tobacco Company, Inc. (Plaintiffs). United States Food and Drug Administration, Margaret Hamburg, Kathleen Sebelius (Defendants). United States district court for the District of Columbia. Civil Case No. 11-1482 (RJL), document 59. Ordered February 29, 2012.

8. Byrne S, Katz SJ, Mathios A, Niederdeppe J. Do the ends justify the means? A test of alternatives to the FDA proposed cigarette warning labels. Health Commun 2015:30:680-93.

9. Wang AL, Romer D, Elman I, Turetsky BI, Gur RC, Langleben DD. Emotional graphic cigarette warning labels reduce the electrophysiological brain response to smoking cues. Addict Biol 2015;20:368-76.

10. Wang AL, Lowen SB, Romer D, Giorno M, Langleben DD. Emotional reaction facilitates the brain and behavioural impact of graphic cigarette warning labels in smokers. Tob Control 2015:24:225-32.

11. Cunningham R. Cigarette package warning size and use of pictures: international summary. Ottawa, Canadian Cancer Society, 2009.

12. Borland R, Yong HH, Wilson N, Fong GT, Hammond D, Cummings $\mathrm{KM}$, et al. How reactions to cigarette packet health warnings influence quitting: findings from the ITC Four-Country survey. Addiction 2009; 104:669-75.

13. International Tobacco Control Policy Evaluation Project. ITC Thailand survey summary. Waterloo, Institute for Population and Social Research, Mahidol University Salaya, and Thai Health Promotion Foundation, 2009.

14. Health Promotion Board. Graphic health warnings on tobacco packaging inspire smokers to quit the habit. Singapore, Health Promotion Board, 2004.

15. Fong GT, Hammond D, Hitchman SC. The impact of pictures on the effectiveness of tobacco warnings. Bull World Health Organ 2009;87:640-3.

16. Australian Government Department of Health and Ageing. Evaluation of the effectiveness of the graphic health warning on tobacco product packaging. Canberra, Australian Government Department of Health and Ageing, 2008.

17. Environic Research Group Ltd. The health effects of tobacco and health warning messages on cigarette packages: survey of youthwave12 surveys. Ottawa, Health Canada, 2007.

18. Vardavas CI, Connolly G, Karamanolis K, Kafatos A. Adolescents perceived effectiveness of the proposed European graphic tobacco warning labels. Eur J Public Health 2009;19:212-7.

19. Huang J, Chaloupka FJ, Fong GT. Cigarette graphic warning labels and smoking prevalence in Canada: a critical examination and reformulation of the FDA regulatory impact analysis. Tob Control 2014:23 Suppl 1:17-12.

20. Azagba S, Sharaf MF. The effect of graphic cigarette warning labels on smoking behavior: evidence from the Canadian experience. Nicotine Tob Res 2013;15:708-17.

21. Organization for Economic Cooperation and Development (OECD). OECD Health Statistics: Non-medical determinants of health: Tobacco consumption. Geneva, OECD, 2014.

22. Fong GT, Hammond D, Jiang Y, Li Q, Quah AC, Driezen P, et al; ITC China Project Team. Perceptions of tobacco health warnings in China compared with picture and text-only health warnings from other countries: an experimental study. Tob Control 2010; 19 Suppl 2:i69-77.

23. Hammond D, Fong GT, McNeill A, Borland R, Cummings KM. Effectiveness of cigarette warning labels in informing smokers about the risks of smoking: findings from the International Tobacco Control (ITC) Four Country Survey. Tob Control 2006;15 Suppl 3:iii19-25.

24. Willemsen MC. The new EU cigarette health warnings benefit smokers who want to quit the habit: results from the Dutch 
Continuous Survey of Smoking Habits. Eur J Public Health 2005; 15:389-92.

25. Cavalcante TM. Labelling and packaging in Brazil (WHO tobacco free initiative toolkit series). Geneva, World Health Organization, 2003.

26. Li J, Grigg M. New Zealand: new graphic warnings encourage registrations with the quitline. Tob Control 2009;18:72.

27. Health Canada. Regulatory impact analysis statement: tobacco products information regulations. Ottawa, Canada Gazette Directorate, 2000.
28. United Kingdom Department of Health. The introduction of picture warnings on tobacco packs: final regulatory impact assessment. London, United Kingdom Department of Health, 2007.

29. Applied Economics. Cost-benefit analysis of proposed new health warnings on tobacco products. Canberra, Commonwealth Department of Health and Ageing, 2003.

30. Hammond D. Tobacco packaging and labeling policies under the U.S. Tobacco Control Act: research needs and priorities. Nicotine Tob Res 2012;14:62-74. 